\title{
Breeding Maize for Low Nitrogen Stress Tolerance: A Review Article
}

\author{
Abayneh Kacharo Kampe* \\ Southern Agricultural Research Institute, Bonga Agricultural Research Center, Bonga, Ethiopia \\ *Corresponding Author: Abayneh Kacharo Kampe, Southern Agricultural Research Institute, Bonga Agricultural Research Center, Bonga, \\ Ethiopia.
}

Received: July 29, 2019; Published: September 24, 2019

DOI: $10.31080 /$ ASAG.2019.03.0661

\begin{abstract}
A review article was aimed to summarize various conventional and biotechnological breeding schemes for evolving low nitrogen stress tolerant varieties. Maize being an outcrossing crop and utilization of biotechnological tools favoured several promising opportunities to manipulate the genetic constitution of the crop for the achievement of several breeding objectives viz, increased productivity, quality, adaptation, stability in production and biotic and abiotic stresses etc. However, the full potential of the crop has not been utilized effectively with respect to abiotic stresses particularly for low nitrogen stress in developing countries in order to feed ever increasing population growth and mitigate continuously occurring climatic and environmental vagaries. Therefore, in order to utilize the full potential of the crop efficiently and effectively in sustainable manner, multi-desplinary team working in collaboration with countries having strong breeding programs and introduction of germplasms from the area of broad genetic diversity and evaluation under representative several environments should be in the first place.
\end{abstract}

Keywords: Maize; Low Nitrogen Stress Tolerance; Breeding Strategies; Breeding Schemes; Biotechnological Tools

\section{Introduction}

Maize (Zea mays L.) belongs to the grass family poaceae and tribe Maydeae, cultivated globally being one of the most important cereal crops worldwide. The genus Zea consists of four species of which Zea mays L. is economically important. The other Zea sp., referred to as teosintes, are largely wild grasses. There is some controversy on the origin of maize, though it is generally accepted that its center of origin is located in Mesoamerica, primarily Mexico and the Caribbean. Maize as we know it today has never been found growing in wild state. Its domestication, probably from a wild teosinte, is believed to have started some 6,000 to 7,500 years ago in the Mexican highlands. Archeological evidence from Mangelsdorf, Reeves, Mac Neish and others and supported by radiocarbon dating, have indicated the existence of wild maize cobs in Mexico 5200-3400 BC, followed by a gradual extinction of wild maize in favor of modern varieties through a more intensive cultivation [1]. The crop was reported in China in 1573, but had probably been taken there at an earlier date by the Portuguese [2]. Because of its wide climatic adaptability maize cultivation expanded rapidly and the grain became soon a part of the local diet as a diversification of traditional root crops (cassava, yams, and sweet potatoes) and various small grains. Maize is now cultivated in more than a hundred countries [2].

\section{Mode of reproduction and floral biology of maize}

Under natural conditions, maize reproduces only by seed production. Pollination occurs with the transfer of pollen from the tassels to the silks of the ear. About $95 \%$ of the ovules are cross- pollinated and about 5\% are self-pollinated [3], although plants are completely self-compatible. There is no asexually reproducing maize. Cell/tissue culture techniques can be used to propagate calli and reproduce tissues or plants asexually; however, with maize cells and tissues, these techniques are difficult [4].

Maize is monoecious with determinate growth habit and highly cross-pollinated where about $95 \%$ of the pistillate flowers on a cob receive pollen from nearby other plants. About $5 \%$ of the kernels on a cob are produced as a result of self-pollination. Maize is generally protandrous, that is, male spikelets mature earlier than the female spikelets. The pollen shedding normally begins 1-3 days before the emergence of silk and continues 3-4 days after the silks are receptive and ready for pollination. According to Poehlman [3], a single tassel may produce as many as $25,000,000$ pollen grains or an average of over 25,000 pollen grains for each kernel on an ear with 800-1000 kernels. Pollen grains are very small, barely visible to naked eye, light in weight, and easily carried by wind. Wind borne nature of pollen and protandry facilitate cross-pollination, but $5 \%$ self-pollination may happen. Pollen grain viability is for about 12-18 hours and thereafter they may be killed in few hours by heat or desiccation. In hot, dry and windy conditions, the pollen shedding may be over early. Under these conditions, the tassel may be injured or the silk may lose the moisture and as a result, barren cobs are produced.

\section{Production status of maize in ethiopia and its utilization}

Maize was introduced to Ethiopia by the Portuguese in the $16^{\text {th }}$ or $17^{\text {th }}$ century (Haffanagel, 1961). The suitability of maize to di- 
verse environments is unmatched with any type of crop. This is because of its wide range of plasticity. It is grown from latitude $58^{0}$ $\mathrm{N}$ to $40^{\circ} \mathrm{S}$, from sea level to higher than $3000 \mathrm{~m}$ altitude and in areas receiving yearly rain fall of 250 to $5000 \mathrm{~mm}$ (Downsell., et al. 1996). Maize growing areas in Ethiopia are broadly classified into four ecological zones based on altitude and annual rainfall (EARO, 2000). These are mid-altitude, most of which lie between 1000 -1770 m.a.s.l and receive $800-1000-1200 \mathrm{~mm}$ of rainfall, the high altitude moist zone, which receive 1200 to $2000 \mathrm{~mm}$ rainfall with an altitude of 1700 to 2400 meters above sea level (m.a.s.l), the low altitude moist zone with less than 1000 m.a.s.l. and the moisture stress zone with 500 to 1800 m.a.s. $\mathrm{l}$ and less than $800 \mathrm{~mm}$ rain fall. Though it is produced in most parts of the country, only three regions out of the nine regions contribute for the largest share. Oromia, Amhara and Southern Nations Nationalities and Peoples regions together account for more than $90 \%$ of the nation's maize production. According to a five years (2003/04 - 2007/08) CSA data, during the past five years, the share of Oromia region was on the average, $60 \%$ of the total Maize production in the country. This was followed by Amhara with 21.67\% and SNNP with 12.55\%. Thus the trend of the national maize production was totally dependent on the production field of the three regions Maize production, particularly in the mid altitude agro-ecology is the highest as compared to other agro ecologies in terms of area coverage, total annual production and productivity. A number of medium to late maturing improved maize hybrids and open pollinated have been released and recommended for commercial production. More than $50 \%$ of the area is annually covered with maize yielding an estimated 2.5tons/ha $[5,6]$.

Maize is increasingly used as an animal feed and fodder crop for both green forage and silage. However, nowadays corn grain is also a key raw material used for making starch, glucose and oil.

Maize starch is used to make sweeteners, as well as such items as disposable forks and spoons. Maize starch is widely used in industrial purposes such as coating for paper and paper products and wallboards for buildings. The pharmaceutical industry also uses maize starch to make pills and other similar products. Recently, high fructose maize syrup has also been made from corn starch. In some countries, alcohol made from maize is blended in fuel for gasoline powered vehicles to reduce emission of pollutants (FAO, 2006).

Maize is a component of canned corn, baby food, hominy, mush, puddings, tamales, and many more human foods. Industrial uses of corn include filler for plastics, packing materials, insulating materials, adhesives, chemicals, explosives, paint, paste, abrasives, dyes, insecticides, pharmaceuticals, organic acids, solvents, rayon, antifreeze, soaps and also used as major study plant for many academic disciplines such as genetics, physiology, soil fertility and biochemistry. It is doubtful that any other plant has been studied as extensively as has the corn plant.

Maize has five phenotypes (sweet, pop, floury, dent and flint) and domesticated in central Mexico around 7000years ago [2]. The maize plant has characteristics of wide adaptability in the different ranges of growing condition. Thus, it has gained adaptation and productivity in all continents through introductions and breeding. The genetic diversity of maize, being an out crossing crop, is very broad for conservation and utilization in breeding programs. Maize landraces exhibit significant morphological variation and genetic polymorphism and are grown from sea level to $3800 \mathrm{~m}$ (Ortiz., et al. 2010).

The major constraints to maize production in sub-Saharan Africa (SSA) include both biotic and abiotic factors. The main biotic factors are pests and diseases and the parasitic weeds, Striga hermonthica (IITA, 2009). The most common abiotic factors are drought, heat, low soil fertility particularly low soil nitrogen, high soil aluminum toxicity, flooding, and salinity (Tuberosa., et al. 2005). The low adoption of improved varieties by farmers (Sibiya., et al. 2013) and the non-use of appropriate farming techniques (Etoundi and Dia, 2008) are also important factors contributing to low yield). Therefore, this paper was principally designed to review genetic basis, strategies, schemes and achievements in maize breeding for low nitrogen stress tolerance.

\section{Main breeding objectives in maize}

\section{Increased productivity and stability in production}

High yield is considered to be the most important trait in any maize breeding program where yields are not to the level of those in the temperate regions of the world. Grain yield in maize like in other crops is a complex and quantitatively inherited traits. Maize yield is cumulative effect of action and interaction of several yield components like, number of ears/plant, kernel rows/ear, kernels/ row, test weight (kernel weight) and shelling percentage. In addition to these primary yield components, there are several secondary yield components and these include nutrient uptake, photosynthesis, translocation, sink size, transpiration and respiration. Grain yield is also affected by maturity duration, standability, and resistance to biotic and abiotic stresses. It has been generally seen that high yielding hybrids developed have longer duration and grain filling period (early flowering and delayed senescence), rapid grain filling period, increased sink size (more kernels per unit area), larger kernels, reduced bareness, higher harvest and shelling indices, shorter plant and tassel, upright leaves, shorter anthesis-silking interval, better adaptability, superior disease and insect-pest resistance and enhanced tolerance to abiotic stresses. Further, two additional features that contribute towards higher yield in maize are ability to respond to higher levels of nitrogen and suitability for cultivation under high plant population.

Good standability contributes enormously towards higher yield in maize. Well-developed root system, strong stem, short plant height, low ear placement, ability to stay green at maturity and resistance to diseases and insects are major factors affecting maize standability [7]. Stability of performance is as important as the improvement fourth economic yield. The selected varieties should have the capability to withstand reasonably well with the attack of important diseases and pests as well as minor f1uctuations in the environmental and crop management practices. 


\section{Maturity}

Breeding for appropriate maturity is an important consideration in maize breeding program. Maize is a short-day plant and accordingly time of flowering is influenced by temperature and photoperiod. Traits related to maturity are days to flower, brown husk, kernel moisture at harvest and black layer formation. Days to silk are considered to be the most reliable index of days to maturity. Genetically, days to maturity are quantitatively inherited trait and selection at inbred line development has been found to be effective to design parents/hybrids with appropriate maturity. And it should also be kept in mind that there is a negative correlation between days to maturity and grain yield and therefore in view of prevailing agricultural system, the emphasis on early or mid or late duration cultivars should be decided. Early maturing cultivars are preferred under rain-fed conditions whereas they escape drought. Long duration cultivars are useful when the cropping system permits them and the crop management is quite good.

\section{Adaptation}

Adaptation, like yield, is a complex objective in maize that is directly affected by cultivar maturity; response to soil fertility level and conservation tillage practices; seedling cold tolerance; and resistance to heat and drought. Indirectly, adaptation is affected by other plant characters such as husk covering, root and stalk quality, disease and insect resistance, and endosperm properties that affect seed storage.

\section{Quality}

There has been remarkable progress in developing new cultivars of maize with increased starch, oil and protein in kernels and in some cases in altering the quality of these constituents. For example, the genes that modify either the structure or the quality of kernel endosperm have been effectively used to develop specialty corns world over [8]. In sweet corn, several genes, such as sucrose (su), shrunken-2 (sh-2), amylose etender (ae), brittle (bt), brittle-2 (bt-2), dull (du), and waxy (wx) have been used to enhance the flavour and tenderness. A breakthrough has been realised with the discovery of opaque-2 (o2) gene by Mertz., et al. [9]. Opaque-2 gene has been shown to double the content of lysine and tryptophan in the maize endosperm. Opaque maize has also proved to be nutritionally superior in feeding experiments. The use of this gene in maize breeding programmes led to development of several stocks/ cultivars often known as Quality Protein Maize (QPM). The high lysine cultivars had initially some inherent problems like low grain yield, dull and soft grain, delayed maturity, susceptibility to some diseases and insects and processing problems due to soft endosperm. However, intensive efforts by CIMMYT led to development of QPM populations and heterotic pools by large scale back-crossing of improved 02 donor stocks followed by recurrent selection to accumulate modifiers to improve kernel vitreousness, hardness and other desirable traits while retaining nutritional superiority.

\section{Biotic and abiotic stresses}

The major constraints to maize production in sub-Saharan Africa (SSA) include both biotic and abiotic factors. The main biotic factors are pests and diseases and (IITA, 2009). The most common abiotic factors are drought, low soil fertility particularly low soil nitrogen (Tuberosa., et al. 2005). The low adoption of improved varieties by farmers (Sibiya., et al. 2013) and the non-use of appropriate farming techniques (Etoundi and Dia, 2008) are also important factors contributing to low yield. The important diseases to be looked into are leaf blights, downy mildews, stalk rots and rusts. Back-cross method of breeding has been found to be effective for disease resistance breeding. In view of large number of diseases affecting maize, emphasis should be on multiple disease resistance breeding. Among several insect pests of maize, stem borer and European corn borer (Ostrinia nubilalis) are considered as serious insect pests worldwide.

Damage due to drought is manifested as top firing, tassel blast and poor seed set which may be due to non-availability of viable pollen, drying of silk or embryo sac abortion. Some morphological traits associated with drought tolerance are synchronised male and female flowering (reduced anthesis-silking interval), small tassel, small leaf area, prolificacy, adaptation to high plant population/density, well developed root system, leaf elongation during drought period, stomatal resistance to water loss, heat tolerance, and low leaf temperature. However, reduced anthesis-silking interval and number of ears/plant under drought are considered the best indicators of drought tolerance in maize and naturally more attention needs to be given to these traits while developing inbreds and hybrids in maize [7].

Low soil nitrogen has been reported as one of the most widely spread problems among small-scale farmers in the tropics [10,11].

Nitrogen is important in maize production because it promotes vegetative growth and maximizes both kernel initiation and kernel set [12]. Nitrogen also plays a key role in the establishment and filling of the kernel sink [12]. Nitrogen is an essential component of all enzymes and it is therefore necessary for plant growth and development. It constitutes about one-sixth of the weight of proteins, which are mainly enzymes [13]. In addition, nitrogen is a basic element of nucleic acids [13]. Nitrogen plays a key role in plant metabolism, especially in protein synthesis during when it has a strong influence on both grain production and protein content (Machado and Fernandes, 2001). It is found in higher amount in leaves, mainly in photosynthetic enzymes, and may account for up to $4 \%$ of the dry weight [13]. Nitrogen is therefore an important element for maize production and there is a strong correlation between $\mathrm{N}$ uptake, biomass production and grain yield in maize [13]

Nitrogen deficiency affects different yield-determining factors. It reduces leaf area and leaf stay-green, thus reducing photosynthetic rate and increasing ear abortion. This is because about $50 \%$ of the leaf $\mathrm{N}$ is directly involved in photosynthesis either as enzymes or as chlorophyll. When $\mathrm{N}$ becomes scarce, plants remobilize $\mathrm{N}$ from older tissues (leaves, stalk) to younger tissues (leaves, grains), leading to early senescence of the older, lower leaf tissues [13]. 
The effect of $\mathrm{N}$ stress on yield depends on the timing of the stress in the growing plant parts. If stress occurs during flowering, it will increase kernel abortion. Nitrogen stress before flowering reduces leaf area development, photosynthetic rate and number of potential kernel ovules. Severe N stress delays both shedding of pollen and emergence of silks. The delay in silking is relatively more severe, therefore increasing the anthesis-silking interval [13]. Nitrogen stress also influences root growth. Under low N, plants favor root growth over shoot growth, and the root/shoot ratio increases even though the total amount of roots is usually less for plants grown under $\mathrm{N}$ stress than under normal $\mathrm{N}$ [13].

Maize is highly sensitive to deficiencies in plant nutrients, especially nitrogen, thus it requires high amounts of fertilizers to produce high yields. This increases production cost [14].

Low soil nitrogen (low $\mathrm{N}$ ) is common in farmers' fields in subSaharan Africa (SSA). In seasons with adequate rainfall, soil nitrogen can be leached below the root zone (Bennet., et al. 1989) and the crop suffers nitrogen deficiency.). Soil nitrogen deficiency is further worsened by the wide spread removal of crop residues for use as animal feed and fuel (Zambezi and mwambula, 1997). The main strategy for maintaining or restoring soil nutrients and increasing crop yields is the application of mineral fertilizers such as nitrogen (N) [15]. The non-availability and high cost of fertilizers limit maize productivity in most developing countries where the majority of smallholder farmers lack resources for purchasing inputs [16]. The best strategy for improving maize production in a sustainable manner in regions with low $\mathrm{N}$ fertility is the selection and development of maize varieties for low $\mathrm{N}$ tolerance. The low $\mathrm{N}$ tolerant cultivars are superior in the utilization of available $\mathrm{N}$, either due to enhanced $\mathrm{N}$ - uptake capacity or more efficient use of absorbed $\mathrm{N}$ for grain production [17].

\section{Genetic basis of maize tolerance to low soil nitrogen}

An understanding of the genetic basis for maize development and yield under low $\mathrm{N}$ conditions is required to accelerate and improve selection efficiency for low $\mathrm{N}$ environments (Bänziger and Lafitte, 1997). Combining ability determines the usefulness of the inbred lines for hybrid maize breeding. The concepts of general and specific combining ability were introduced by Sprague and Tatum [18]. Hallauer and Miranda (1988) defined general combining ability (GCA) as the mean performance of a line in all its crosses, expressed as a deviation from the mean of all crosses. It is the average contribution an inbred makes to hybrid performance in a series of hybrid combinations in comparison to other inbreds in the same series of hybrid combinations and specific combining ability (SCA) is the contribution of an inbred to hybrid performance in a cross with a specific to other inbred in relation to its contributions in crosses with an array of other inbreds. SCA can also be defined as the specific ability of two inbred lines to complement each other to produce superior hybrid performance. GCA effects may be used to estimate gene action of traits. In statistical terms, GCA effects indicate primarily additive gene action. Specific combining ability is associated with non-additive genetic effects which are not predictable but are ephemeral and therefore hard to predict with statistical models [19]. A high GCA effect for a particular trait in a parent indicates the presence of additive gene effects for the trait in the concerned parent. It would be expected that when parents possessing high GCA effects were crossed, a large proportion of progenies would have high values for the trait concerned, facilitating selection for that trait (Falconer, 1981). Effects of GCA can be used to select superior genotypes under low N conditions. High GCA effects under low $\mathrm{N}$ may reflect the presence of the desired trait for low $\mathrm{N}$ tolerance. Combining ability analysis is important in identifying the best parents or parental combinations for a hybridization program or for population improvement programs [20]. Various biometrical approaches are available to assess the breeding value of the parents and to assess the genetics of the traits under transfer Diallel analysis is used to estimate GCA and SCA effects and their implications in breeding [21,22]. Griffing [22] proposed an analysis for diallel mating systems that estimate the general and specific combining abilities of lines and hybrids. Line $\mathrm{x}$ tester analysis (Kempthrone, 1957) is another approach often.

\section{Breeding strategies for developing low $\mathbf{n}$ tolerant maize varieties}

Maize selection for low $\mathbf{n}$ tolerance

Maize genotypes differ widely with regard to $\mathrm{N}$ nutrition, especially low $\mathrm{N}$ tolerance and nitrogen use efficiency [23]. This variation in nitrogen use efficiency indicates that this trait may be genetically determined and could be improved by breeding [24]. An appropriate breeding strategy could be used to develop genotypes that tolerate low $\mathrm{N}$ stress and produce high grain yield under both low soil $\mathrm{N}$ and optimal conditions. However, few studies have been conducted because it has often been assumed that there is no interaction between $\mathrm{N}$ levels and cultivars for grain yield [24]. Important considerations in establishing a selection program for stress tolerance should be whether OPVs, hybrids or both types of products are needed, and what human, financial, and physical resources are available for experimental work. Additional important factors include the choice of germplasm, breeding methodology, selection environments, and essential data to collect.

According to Bänziger., et al. [13], breeding methodologies in the tropics have been strongly influenced by maize breeding in temperate areas. In temperate environments, maize is grown under relatively stress free conditions and yields obtained at the farm levels are comparable to those obtained from experiment stations. In the tropics maize is frequently stressed in farmers" fields and yields are far below those obtained on breeding stations. Therefore, selection under high yielding conditions may not be suitable to increase yields in farmers" fields [13].

Heritability and genetic variance for grain yield usually decreases under abiotic stress as yield levels fall [13]. Difference between entries is non-significant and the expected selection gain is less than under conditions where yields are high. Because of the high genotype $\mathrm{x}$ environment interactions, stress experiments often produce rankings that differ significantly from one experiment to another, making it difficult to identify the best germplasm [13]. 
Developing maize genotypes with tolerance to N stress is complex. This is due to various factors, including the largely polygenic nature of the tolerance, alleles related to stress tolerance are present in most elite maize populations at a relatively low frequency and the difficulties commonly encountered in field evaluations; therefore, selection under controlled, low $\mathrm{N}$ would be as an effective means of developing varieties capable of tolerating low $\mathrm{N}$ [25]. Since yield is controlled by a large number of minor genes, its improvement under low $\mathrm{N}$ environments will depend on how the respective genes respond to the stress [26].

Bänziger and Lafitte (1997) proposed direct selection (i.e. selection under conditions where the stress factor occurs uniformly and predictably as the more appropriate method to maximize selection gains under low $\mathrm{N}$. This method was often superior to indirect selection in targeting stress environments.

Presterl., et al. (2002) developed hybrids under low and high $\mathrm{N}$ conditions and reported that the average yields of the hybrids developed at low $\mathrm{N}$ conditions were $11.5 \%$ higher in low $\mathrm{N}$ conditions than those selected under high $\mathrm{N}$ conditions. There was no significant difference in yield between the two hybrid types under high $\mathrm{N}$ conditions. In addition, the N-efficient hybrids showed significantly higher $\mathrm{N}$ uptake at low $\mathrm{N}$ levels than the hybrids selected under high N. No differences in N-utilization efficiency were observed (Presterl., et al. 2002).

Lafitte and Edmeades [17] and Bänziger., et al. (1999) observed that recurrent selection under drought has a spillover effect on performance under low N conditions. Lafitte and Banziger (1997) reported gains in grain yield of about $3.4 \%$ per year under low $\mathrm{N}$ conditions when selecting for drought tolerance. They attributed this to reduced ear abortion and delayed leaf senescence, which are improved when developing drought tolerance. From their study, an increase in grain yield was achieved under low $\mathrm{N}$ while, under high $\mathrm{N}$, grain yield was reduced after a single cycle of selection among half-sib families of a tropical maize population.

Using full-sib family selection to develop maize cultivars tolerant to low $\mathrm{N}$ under selection conditions of low and high $\mathrm{N}$, (Omoigui., et al. 2006) obtained genetic gains in grain yield of $2.3 \%$ and $1.9 \%$, under low and high $\mathrm{N}$ after one cycle of selection, respectively. They also recorded an increase in stay green by $17 \%$ and $4.7 \%$ after cycle-1 under low and high $\mathrm{N}$, respectively. These results suggest that mechanisms conditioning grain yield under low $\mathrm{N}$, differed from those under high $\mathrm{N}$ conditions (Omoigui., et al. 2006).

\section{Sources of germplasm}

The selection of appropriate germplasm is critical, requiring careful consideration of all available information. A wrong choice cannot be corrected by using sound and efficient breeding methodologies. There are several approaches a breeder can take to develop low $\mathrm{N}$ tolerant germplasm.

Improving locally adapted, elite germplasm for low nitrogen tolerance

In a comparative evaluation study of landraces and improved varieties under low N, Lafitte., et al. (1997) reported that improved varieties out-yielded landraces but landraces were superior in grain $\mathrm{N}$ concentration. In the same study, improved varieties were not consistently superior to landraces in $\mathrm{N}$ recovery, above ground biomass or in the fraction of $\mathrm{N}$ partitioned to the grain under low $\mathrm{N}$, which would reflect their efficiency in the use of $\mathrm{N}$.

CIMMYT evaluated a wide range of landraces for low $\mathrm{N}$ tolerance, but there were few (about 3\%) that compared favorably with elite, adapted germplasm for low $\mathrm{N}$ tolerance, and even fewer that compared favorably with elite, adapted germplasm under high yielding conditions. Thus, improving adapted, elite germplasm for low $\mathrm{N}$ tolerance is probably nearly always better than working with landraces. A compromise approach would be to create synthetic populations from local landraces and improved, adapted varieties (Heuberger., et al. 1995; Kling., et al. 1997).

Another study done by Miti., et al. [26] using S1 selection for tolerance to low $\mathrm{N}$ among ninety-six maize landraces indicated that, some maize landraces that tolerated the stress caused by low $\mathrm{N}$ more than improved maize varieties and concluded that there was adequate genotypic variation for low $\mathrm{N}$ tolerance among maize landraces which could be improved by selection.

Improving non-adapted but low nitrogen tolerant populations for local adaptation

Screening for general adaptation by the breeder may be necessary, and only the best adapted among the introduced stress-tolerant materials should be used. Adaptation can usually be further improved through selection, and for many breeders it is easier to select for adaptation (suitable maturity, disease resistance, and yield potential) than for low $\mathrm{N}$ tolerance. A breeder may want to use such germplasm or any other known source of low $\mathrm{N}$ tolerance. Such materials may not be well adapted in terms of disease resistance, maturity, etc., to the target environment.

\section{Formation of new breeding germplasm through introgression}

The third and more complex strategy is to develop a new breeding population by introgression of locally adapted germplasm with source low $\mathrm{N}$ tolerant germplasm. Introduced stress tolerant lines may be used directly as one of the parents in a hybrid that is then released. More often, however, stress-tolerant lines need to be introgressed into local germplasm. After the initial cross between source and recipient line, selection and or inbreeding can be initiated either immediately or after one or more recombination or backcrosses. Repeated recombination before initiating inbreeding increases the chances of obtaining inbreds with stress tolerance and good agronomic performance. Backcrossing is advantageous if one parent has more loci with favorable alleles than the other, if the parents are diverse, or if the level of dominance is high [27].

\section{Secondary traits in selection for low $\mathrm{N}$ tolerance in maize}

A secondary trait is a trait for which the breeder can select to achieve the progress expected from selecting for an original desired trait [19]. This is called indirect selection, also defined as selection applied to some character other than the one it is desired to improve [19]. 
Breeders" primary interest is in grain yield. However, other secondary traits may be used to assess low $\mathrm{N}$ tolerance in maize because the secondary traits can improve the precision with which low $\mathrm{N}$ tolerant genotypes are identified, compared to measuring only grain yield under low $\mathrm{N}$ stress. This is because, under stress, the heritability of grain yield usually decreases, whereas the heritability of some secondary traits remains high, while at the same time the genetic correlation between grain yield and those traits increases sharply [28]. Secondary traits can measure the degree to which a crop is stressed under low $\mathrm{N}$, or, if observed before or at flowering, they can be used for selecting desirable parents [13]. Moreover, if observed before maturity secondary traits can be used for preliminary selection when there is not sufficient time between two consecutive growing seasons [13].

Edmeades., et al. (1997) established that an ideal secondary trait should be genetically associated with grain yield under stress, highly heritable, genetically variable, cheap and fast to measure, stable within the measurement period, not associated with a yield loss under unstressed conditions. A secondary trait should be observed at or before flowering so that undesirable parents are not crossed. Finally, it should be a reliable estimator of yield potential before final harvest. According to Bänziger., et al. [13], a secondary trait should not be only related to low $\mathrm{N}$ tolerance, but the use of this trait together with grain yield in selection should provide greater breeding progress than progress obtained using grain yield alone. Thus, not only must secondary traits be identified, but their value in breeding must be proven [13]. Plant breeding for nitrogen use efficiency, which is a combination of the efficiency of uptake, translocation and utilization of $\mathrm{N}$ [29], could be accelerated in maize by the selection of secondary traits that possess high heritability and positive correlation with productivity [13]. Bänziger and Lafitte (1997) showed that the use of secondary traits plus yield improved selection gains for maize yield under low $\mathrm{N}$ by $20 \%$ compared to selection for yield alone, and the gains increased as $\mathrm{N}$ deficiency intensified [30].

Since the 1990s, breeding for low $\mathrm{N}$ tolerant maize hybrids for farmers in developing countries has been an objective of CIMMYT (Edmeades., et al. 1997). The selection criteria identified by CIMMYT for maize tolerance to Low- $\mathrm{N}$ include grain yield at high and low $\mathrm{N}$, plant height under low $\mathrm{N}$, ear leaf area, number of ears and kernels per plant [17]. In maize, phenotypic and genotypic correlations were highly significant between grain yield, kernel number and kernel weight under low $\mathrm{N}$ [31]. Genotypes with a short anthesis-silking interval and a high number of ears per plant are efficient in remobilizing $\mathrm{N}$ from the stover to the grain, particularly during the early stage of embryo development thereby reducing embryo or ear abortion [32].

Anthesis-silking interval has moderately high heritability and is correlated with grain yield under low $\mathrm{N}$ conditions (Bänziger and Lafitte, 1997). However, anthesis-silking interval only explained $25-35 \%$ of variation in grain yield and could not be used alone (Edmeades., et al. 1997). Vasal., et al. [25] observed that in selecting for tolerance to low $\mathrm{N}$, anthesis-silking interval and number of ears per plant were effective and this was in accordance with the findings of Lafitte and Bänziger (1997), who reported that in addition to these, leaf senescence was also important. Bänziger., et al. [13] reported that the grain yield, number of ears per plant, anthesis-silking interval and leaf senescence were important in identifying superior genotypes under low $\mathrm{N}$.

Miti., et al. [26] evaluated grain yield, number of ears per plant, anthesis-silking interval, leaf senescence, leaf rolling, tassel size and grain texture in S1 plants from 96 land races for their relevance in selecting genotypes tolerant to low $\mathrm{N}$ and reported that secondary traits should be used to supplement grain yield to identify superior genotypes under low $\mathrm{N}$ conditions. They suggested that grain yield, tassel size and number of ears per plant should be used in selection indices to identify genotypes that tolerate low $\mathrm{N}$. By using a selection index, selection for several traits can be made simultaneously and breeders" decisions are based on the relative weights they give to each trait [33]. Badu-Apraku., et al. (2011a) reported that, under low $\mathrm{N}$, the most reliable traits were days to anthesis, days to silking, stay green characteristic, anthesis silking interval, plant height, number of ears per plant, ear aspect and plant aspect, but concluded that progress in selecting for improved grain yield is possible using only the number of ears per plant, ear aspect, plant aspect and anthesis-silking interval.

\section{Breeding schemes (methods)}

The extent to which selection for low $\mathrm{N}$ stress tolerance can be included in a breeding program depends on the breeding scheme used. In any breeding program, however, the following need to be clearly defined:

- The type of product to produce: OPV, hybrid, top cross hybrid, etc.

- The most important characteristics of the product: maturity, grain characteristics, necessary stress tolerance and disease resistance, etc.

- The strategy for developing and deploying the product.

- All breeding programs use a step-wise selection procedure to identify the best performing progenies, given limited resources. First, a large number of progenies are evaluated with few replicates and at a few sites (screening), then the more successful progenies, or their descendants, are evaluated with more replicates and at more sites (testing).

Evaluation under low $\mathrm{N}$ stresses should be included in the screening phase, and the results should be combined with results obtained under unstressed conditions. Only the best germplasm (i.e., genotypes that possess stress tolerance and have good yields under optimum conditions) should be advanced to the testing phase. The testing phase should include sites that are representative of conditions under which farmers grow maize. If $\mathrm{N}$ stress is frequent in farmers' fields, these conditions must be included. These multi location trials need to be set up in a manner that con- 
siders the difficulties of stressed sites. One should not hesitate to increase the number of replicates and reduce the number of entries in such trials.

\section{Population improvement schemes}

Maize provides a wide array of options with respect to breeding methodologies. One choice is between intra-population and interpopulation improvement methods.

Intra-population population improvement schemes for low Nitrogen

Within intra-population improvement methods, alternatives are

- Individual plant versus family selection.

- Non-inbred families versus selfed progenies.

- Per se performance versus test cross performance.

Within inter-population improvement methods, alternatives are

- Test crosses involving individuals versus families.

- Half-sib versus full-sib test cross progenies.

- Parental versus non-parental testers.

Individual plant selection schemes

Two common procedures are simple mass selection and stratified mass selection [21]. The procedures are not recommended for traits with relatively low heritability, such as grain yield only but used with other secondary traits under low $\mathrm{N}$ stress. They can be quite effective for highly heritable traits, such as selecting for disease resistance after introgression of an exotic stress-tolerant but disease susceptible genotype into well-adapted, disease resistant germplasm.

\section{Mass selection}

This is the oldest, simplest and least expensive method of selection for cross pollinated crops, particularly maize. This consists of selection of ears on the basis of plant and ear characteristics and bulking of seeds of harvested ears to grow the following generation in which again another cycle of selection can be initiated. Cycle of selection is completed in one season. This process can be repeated for several cycles till substantial gains are realized. This method although simplest in operation has certain limitations like inability to identify superior genotypes on the basis of phenotypic performance alone and no control over pollen parent where inferior plants also contribute their pollen. Further, rigorous selection for specific plant trait often leads to inbreeding. Additional limitation is that selection is based on single plant, therefore the role of environment may affect the plant performance and one may select the plants which may be potentially not up-to mark. Therefore, this method has been subjected to some modifications.

\section{Modified Mass Selection}

This has been proposed by Gardner in the year 1961. In this method, the source population in which selection has to be done is

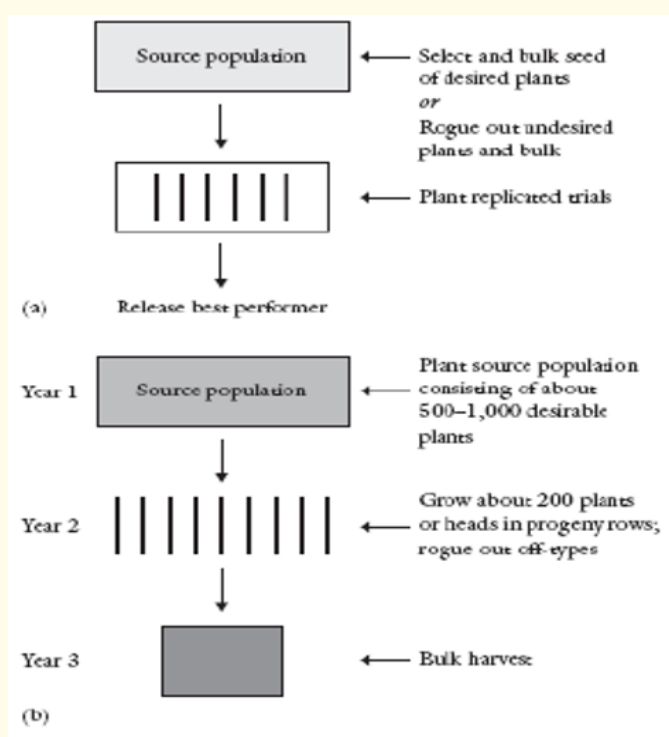

Figure 1: Generalized steps in breeding by mass selection.

grown in isolation at a low plant density to allow better phenotypic expression of each individual plant. The whole area is divided into sub plots or grids. Selection for superior ears on superior plants is done in each grid. Selected ears across the grids are bulked. This method of selection is also known as stratified mass selection. A few cycles of mass selection may successfully eliminate the most susceptible fraction of the population before switching over to a family-based improvement method. This is a good option where human, financial, and physical resources are limited.

\section{Family-based selection: per se}

Family-based selection methods result in greater gains when traits under selection are complex and of low heritability, but are more demanding in resources, record keeping and overall management. Progenies such as half-sib, full-sib, S1, S2, etc., are evaluated. Progress can be expected from any one of these methods. The choice of method will be guided by the availability of off-season test sites, the ability to store remnant seed, the choice of product (variety, hybrids or both), desired traits, heritability, progeny seed quantities, the degree of control over pollination (both parents or only one parent), and the time required to complete a selection cycle.

\section{Half-sib improvement}

Hal-sib refers to a plant or family of plants with a common parent or pollen source or methods in which Detasseling half-sibs (females) are pollinated with pollen from a bulk of all half-sibs (male) are commonly practiced using an un replicated layout. Because the females are Detasseling ASI cannot be observed. For low $\mathrm{N}$ tolerance improvement, it is therefore more desirable to plant replicated trials of half-sib progenies and use remnant seed for recombination of selected families. Heritability of yield from half-sib progenies is lower than that for other types of progenies. However, where resources are limited, this may be the most cost-effective selection scheme. An example of the half-sib selection procedure as used with corn follows (Figure 2). 


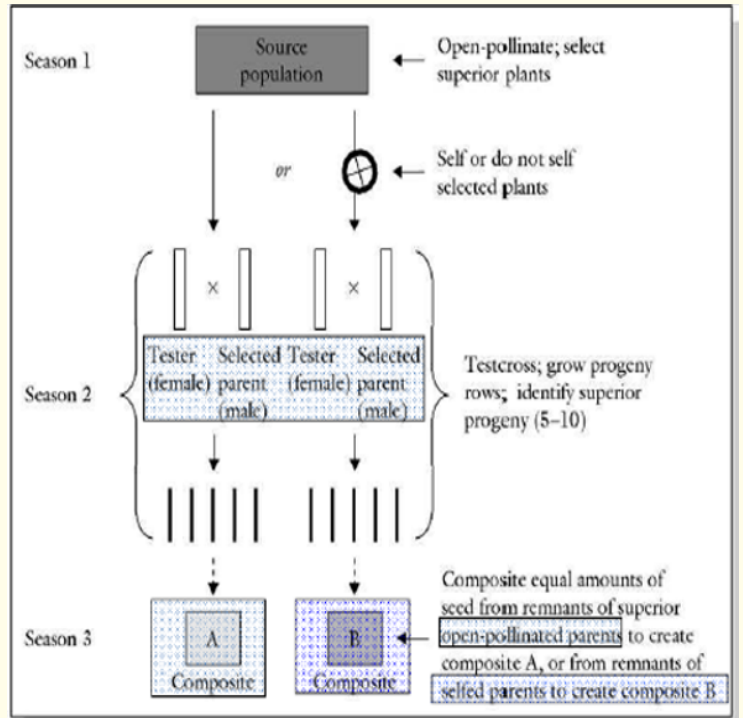

Figure 2: Half -sib selection with a proaenv test.

\section{First season}

Select 50 to 100 plants with desired features from an open pollinated source population, keeping the seed harvested from each plant separate. The seed from each plant will constitute a different breeding line.

\section{Second season}

Using seeds harvested from open pollinated plants in the previous season, grow a progeny test of each line in an isolated area. Retain the remnant seed.

\section{Third season}

The population is reconstituted by compositing equal quantities of either (a) seed harvested from the 5 to 10 superior progenies, or (b) remnant seed from the 5 to 10 lines with superior progeny performance. Grow the composite in isolation with open pollination to obtain new gene combinations. In (a), one-half of the genes come from a random assortment of pollen from the lines in the progeny test, and in (b), one-half of the genes come from a random assortment of pollen from the original source nursery. As an alternative to growing the composite in isolation, plants may be hand pollinated from a composite of pollen. Seed harvested in the third season may be: increased as a new open pollinated cultivar, planted as a source population to start a new selection cycle, or planted as a source population for isolation of new inbreds in a hybrid breeding program.

\section{Full-sib family recurrent selection}

This has been used extensively at CIMMYT to improve populations for drought and low $\mathrm{N}$ tolerance. Replicated trial sets of full-sib progenies are evaluated under drought, low $\mathrm{N}$ and wellwatered, well-fertilized conditions. Selection is made based on performance in all environments and considering other factors such as disease resistance, grain texture etc. A single cycle of selection requires at least two seasons to complete.

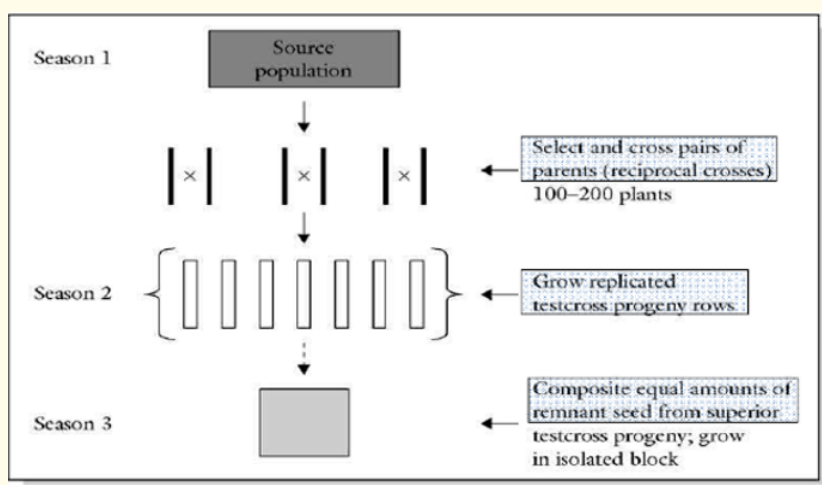

Figure 3: Full-sib breeding method.

\section{Selfed progenies}

When breeding procedures are based on selfed progenies, it takes longer to complete a cycle of selection, but this approach significantly improves tolerance to inbreeding over time. Formation of many S1 or S2 progenies is recommended. These can be prescreened in unreplicated observation nurseries under low $\mathrm{N}$ and the selected fraction (perhaps only $30 \%$ of the original progenies) can be examined in more detail in replicated evaluations under, say, $\mathrm{N}$ stressed and well-fertilized conditions. Where pre-screening in the main season is possible, disease susceptible progenies can be eliminated. Seed supplies may become limiting. This can be solved by using selected S2 ear bulk seed developed from each S1 progeny. To maintain population gains over longer periods, it is recommended that no fewer than 20-40 inbred progenies be recombined.

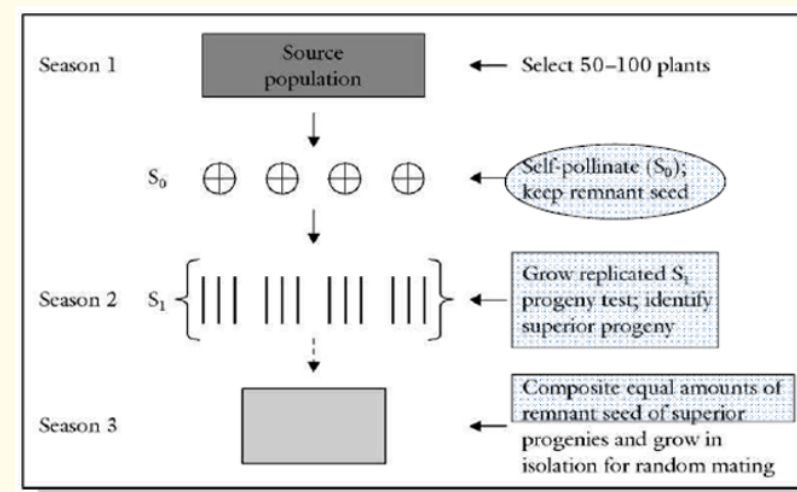

Figure 4: Selfed-progeny performance breeding method.

\section{Half-sib selection with testcross performance}

In this procedure the selection of the half-sib lines to composite is based on testcross performance rather than progeny performance. An example of the procedure as used with corn follows (Figure 5).

\section{First season}

Prior to flowering, select 50 to 100 plants with desired plant characters from a source population: (a) pollinate a tester parent plant with pollen from each of the selected plants and harvest 


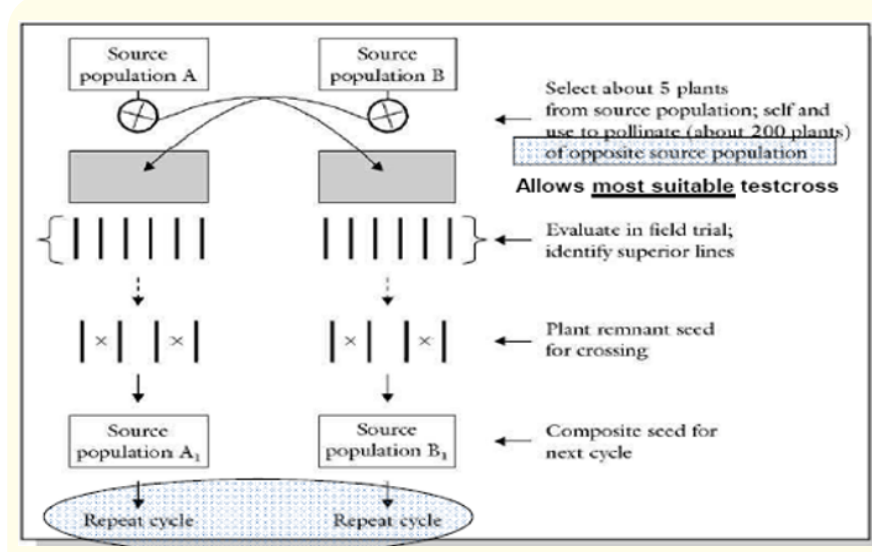

Figure 5: Half-sib selection with a testcross.

crossed seed from the tester parent and open pollinated seed from the selected plants, keeping identity of each seed lot; or (b) with pollen from each selected plant, pollinate a tester plant and selfpollinate the selected plant. Harvest crossed seed from tester parent plants and selfed seed from selected plants, keeping identity of each seed lot.

\section{Second season}

Grow testcross progenies.

\section{Third season}

Reconstitute the population (a) by mixing equal quantities of open pollinated seed from 5 to 10 selected plants with superior testcross progeny performance; or (b) by mixing equal quantities of selfed seed from 5 to 10 selected plants with superior testcross progenies. Grow the seed composite in an isolated seed plot with open pollination to obtain new gene combinations. The half-sib testcross procedure permits control over the testcross parents so that a more precise evaluation of the genotype of the selected plant is obtained than from growing a progeny obtained by open pollination as in the previous procedure. If the tester is an inbred line, plants in each of the lines in the testcross progeny nursery will have one parental gamete in common. Procedure (b) would be superior to procedure (a) because only genes from the plants with superior testcross progenies enter into the gene pool of the composite, whereas in procedure (a) one-half of the genes originate from a random selection of pollen from the source population.

Interpopulation improvement alternatives for low nitrogen stress

Two commonly used methods include reciprocal recurrent selection/half-sibs (RRS-HS) (Comstock., et al. 1949) and reciprocal recurrent selection/full-sibs (RRS-FS) [7,33]. Such schemes result in improved populations and superior OPV products as well as improving hybrid-oriented features of the two populations by increasing the level of heterosis between them. In addition, these schemes allow the extraction of early generation lines with good general combining ability (GCA), provide a sound basis for recycling early generation lines, identify superior testers on a continuous basis, and may identify new conventional and non-conventional hybrids.
The schemes are not particularly suitable if the populations do not tolerate inbreeding, and the per se performance of lines and parent populations is ignored during selection. The original schemes also recommend evaluating $\mathrm{S} 0$ test crosses and recombining the parental S1 seeds of good performing plants. The modified schemes attempt test crosses (HS or FS) on S1 or S2 progenies and also permit selfed progeny evaluation for elimination of undesirable progenies. The RRS-FS schemes have an added advantage over RRS-HS, in that only $50 \%$ of resources are spent on test cross progeny evaluation trials. Both original and modified schemes permit selection for low $\mathrm{N}$ at one or more stages during the selfed progeny regeneration and evaluation stages and during the evaluation of test cross progenies. These types of inter-population improvement schemes are not a necessary requirement for hybrid development, but from a long-term perspective they should generate useful early generation lines.

\section{Procedures in reciprocal half-sib recurrent selection}

- Season 1: 100 plants selected in population A (Cycle 0) are selfed and crossed to 6 or more random plants in population $B$ and vice versa for selected plants in population B. The selfed seed of each plant is put in storage.

- Season 2: The 100 half-sib families of population A and the 100 from population B are evaluated in replicated trials. The top 10 half-sib families are selected from each population.

- Season 3: The 10 plants in population A that had superior HS progeny performance in season 2 are intercrossed to form a cycle 1 population using the selfed seed produced in season 1. The 10 plants in population $B$ are treated in a similar manner.

- Season 4: Cycle 1 seed of populations A and B is used to conduct the next cycle of selection as that described for season $1-3$.

NB

This method is used for the simultaneous improvement of two populations. Two segregating populations are selected, one designated $\mathrm{A}$ and the other B. Population $\mathrm{A}$ is used as a tester to evaluate individuals in Population B and vice versa.

Procedures in reciprocal full-sib recurrent selection

- Season 1: Two hundred phenotypically desirable S0 plants in population A (Cycle 0) are paired with 200 plants in population B (cycle 0). For each of the pairs, the plants are selfed and crossed to the other member of the pair.

- Season 2: The 200 Full-sib families are evaluated in replicated trials and the superior $10 \%$ are selected.

- Season 3: The selfed seed is used to intercross the 20 individuals of each population independently that were members of the 20 top full-sib families. The intercrossed seed of population $A$ and $B$ represent the cycle 1 populations.

- Season 4: The procedure used in seasons 1 to 3 is repeated to obtain the other subsequent cycles. 
NB

This method of inter-population improvement used when the commercial product intended is hybrid seed. A cycle of selection is completed in the fewest number of seasons by the use of plants from which selfed and hybrid seed can be obtained.

Development low $\mathbf{n}$ tolerant lines and hybrids

Inbred lines of corn are populations of identical (or nearly identical) homozygous plants usually developed by self-pollination. Inbred lines are (a) the products from inbreeding heterozygous plants from open pollinated populations until homozygosity is reached or (b) products from inbreeding segregating populations following a cross between two inbred lines. The latter is comparable to the hybridization procedure in breeding self-pollinated species. In producing inbred lines in corn, pollination is controlled. Different type of segregating populations tolerant for low $\mathrm{N}$ stress can be used as the source in line development; open pollinated cultivars (OPC), synthetic cultivars, single crosses, backcrosses, double crosses, related line crosses, and exotic germplasm. In maize as soon as ear shoots are visible in the leaf axils of a plant, a small paper 'shoot-bag' is placed over the shoots; this allows the ear to continue growing and the silks to emerge but prevents any pollen from falling on the silks. Progeny of selected plants are grown separately from the selfed seed in the next season. Again selection is made for the superior progeny and selfed. This processes is continue to get superior homozygous inbred from F5-F7.

The evaluation of lines in all possible crosses in order to identify the best hybrid combinations is, therefore, the most important and difficult aspect of hybrid maize development for low nitrogen stress. Types of hybrids emphasized (top cross hybrids, double, triple, or single-cross hybrids) will depend on the stage of hybrid development and seed industry infrastructure, but an evolution from non-conventional to conventional and from multi parent to twoparent hybrids seems logical. Populations improved for drought or low $\mathrm{N}$ tolerance are useful sources for extracting low $\mathrm{N}$ tolerant inbred lines.

\section{Line - hybrid correlations}

The relationship between the performance of inbred lines and their hybrids is an important issue in hybrid development. Inbred line information indicative of hybrid performance is desirable to reduce hybrid trial evaluations. The number of potential single crosses to evaluate increases substantially with the number of parental inbreds. The possibility of using inbred line information, as indicative of hybrid performance, is desirable to reduce the number of hybrid evaluations. The correlation between parental inbreds and hybrids depends on the trait. In general, the correlation is relatively high for some additively inherited traits (e.g., plant morphology, ear traits, maturity, quality characters) but is relatively low for grain yield. The correlation for grain yield has been consistently positive and significant but not high enough to predict hybrid performance. The correlations between parental genetic diversity estimated with molecular markers, pedigree, or phenotypic traits and hybrid performance also have been too low to have predictive value (Melchinger 1999). Methods based on linear mixed models have been adapted to maize to predict performance of inbreds in untested environments or hybrid combinations (Bernardo 1999).

Lafitte and Edmeades [17] reported that the correlation between S2 per se and top cross performance under low N was only 0.22. Betran., et al. (1997) have reported correlations of around 0.4 between S3 per se and top cross performance for some stressrelated traits under drought, indicating that inbred lines insufficiently predict hybrid performance under drought or low $\mathrm{N}$. The practical implication of these findings is that low $\mathrm{N}$ evaluations of lines may be justified in early generations when numbers of progenies are yet very large, but the performance of advanced lines is best evaluated in hybrid combination. In a given set of inbred lines, " $\mathrm{N}$ ", the number of all possible crosses is given as $\mathrm{N}(\mathrm{N}-1) / 2$. When $\mathrm{N}$ is large, it becomes impossible to make all possible combinations for evaluation. For example, evaluation of 1000 lines in all possible single cross combinations would involve [1000(999)] $/ 2=499,500$ hybrids, an impractical number of entries to test in any breeding program.

\section{Choice of appropriate testers}

Evaluation of inbred lines per se has been shown to have little value because of the inconsistency of correlation between characters of inbreds and their performance in $\mathrm{F} 1$ crosses. The breeder wants to identify a limited number of lines with sufficient genetic potential before their evaluation in specific hybrid combinations is attempted.

Davis (1927) and Jenkins and Brunson (1932) suggested the use of a common tester to evaluate inbred lines for general combining ability. The choice of testers is a critical yet difficult decision in hybrid development. Appropriate choices will have a strong effect on the outcome of a program designed to identify stress tolerant hybrids. Testers can be inbred, non-inbred, populations, synthetics, or hybrids. The choice involves a blend of theoretical and practical considerations. For example, should one use a broad or narrow genetic base tester, high or low yielding, one with high or low frequency for stress tolerance traits, good or poor GCA, one or several testers, and related or unrelated testers? Testers with a low gene frequency for the selection traits emphasized are theoretically attractive but are not commonly used, particularly regarding yield. For drought and low N selections, they might be more practical, since many conventionally developed testers have never been selected for drought or low $\mathrm{N}$ tolerance. A desirable tester must facilitate discrimination among genotypes for combining ability and desirable traits, simultaneously identify useful hybrid products for direct use, and be compatible with a practical maize breeding program [25]. For practical purposes, using the same testers for evaluating combining ability under low N stressed conditions, as they are used for evaluating combining ability under well-watered, well fertilized conditions. This common tester approach is what is now referred to as the Test-cross or Top-cross test, whereby lines at a specified stage of inbreeding are crossed to a common parent referred to as the tester, and the hybrids formed in this manner re- 
ferred to as test crosses or top crosses. Since the tester is the same for all lines under evaluation, differences in performance among top crosses will re£1ect differences in the general combining ability of the lines.

\section{Development of hybrids}

The term heterosis was coined by Shull [34]. Heterosis is the vigor manifested in hybrids and represents the superiority in performance of hybrids compared with their parents [33]. Hybrid vigor in maize is manifested in the offspring of inbred lines with high specific combining ability [33]. Heterosis is important in maize breeding and is dependent on expression of over dominance and epistasis. The manifestation of heterosis usually depends on genetic divergence of the two parental varieties, and genetic divergence of the parental varieties is inferred from the heterotic patterns manifested in a series of variety crosses [33]. Heterosis may be defined in two basic ways. Hallauer., et al. [33], proposed methods to measure high-parent heterosis and mid-parent heterosis of a hybrid relative to is parents: High-parent heterosis is the performance of a hybrid relative to the performance of its best parent expressed in percentages while mid-parent heterosis is the performance of a hybrid relative to the average performance of its parents expressed in percentages. In maize, heterosis can be maximized by crossing inbred lines belonging to different heterotic groups [35]. Many heterotic groups have been developed by maize breeders and inbred lines that are complimentary to other inbred lines can be considered as being in opposite heterotic groups. For example, heterotic group A and B designate broad classes in maize with diverse genetic base that are complimentary and result in expression of heterosis after crossing [36]. Crossing maize varieties from these complementary groups will result in expression of heterosis. On the other hand, synthetic varieties are developed from inbred lines belonging to the same heterotic group. It is therefore important to have knowledge of the heterotic groups of inbred lines before they can be used for variety development $[35,36]$.

\section{Line and hybrid improvement by introgression}

The most important decision in the improvement line and hybrid performance is to identify the source germplasm (lines, synthetics, populations, hybrids, etc.) most likely to contribute the most favorable genetic factors for drought or low $\mathrm{N}$ tolerance to the elite recipient line or hybrid. Several methods of selection of the donor source have been described by Beck., et al. [37]. The objective is to identify source germplasm with the highest frequency of favorable dominant alleles that are not present in an elite hybrid. A pragmatic approach that is taken by many breeders is first to evaluate source inbred lines for per se adaptation to the target environment. Again, many lines, maybe 60 to $80 \%$, may be discarded in this step, and only lines with desirable disease resistance, maturity, and grain characteristics are then crossed to the local tester lines and their combining ability and heterotic response determined under managed stress and unstressed conditions. Introduced stress tolerant lines may be used directly as one of the parents in a hybrid that is then released. More often, however, stress-tolerant lines need to be introgressed into local germplasm. After the initial cross between source and recipient line, selection and or inbreeding can be initiated either immediately or after one or more recombination's or backcrosses. Repeated recombination before initiating inbreeding increases the chances of obtaining inbreds with stress tolerance and good agronomic performance. Backcrossing is advantageous if one parent has more loci with favorable alleles than the other, if the parents are diverse, or if the level of dominance is high [27].

Biotechnology applications in maize breeding for low $\mathrm{N}$ stress

Biotechnology tools continue to develop rapidly, opening new possibilities. So far, in most maize breeding programs, applications will be for:

- $\quad$ Fingerprinting of inbred lines: the information can be used to identify lines used as parents in a hybrid, or to predict heterosis in crosses by estimating genetic distance between parents.

- Line conversion: a trait (or traits) of interest is transferred from a donor line to a recipient elite inbred line. Where a single trait is to be transferred, marker-assisted backcrossing can reduce the need for backcrosses from the usual four to five to around two. At the same time, the amount of "linkage drag" associated with transfer of unwanted parts of the donor genome to the recipient line is reduced [4].

\section{Marker-assisted Selection (MAS) for Low N tolerance}

Marker-assisted selection will be an effective way to save time in breeding if

- The heritability of the trait is high and field evaluation is very costly or simply cannot be done at your location.

- Environmental effects are significant, heritability is low, and a classical selection is expensive or slow, or if the conditions for selection are only presents occasionally (e.g., selection for drought tolerance in the rainy season).

- If we want to backcross a known gene into an inbred line as rapidly as possible. Because of the importance of anthesissilking interval, CIMMYT tried to identify quantitative trait loci (QTL) for ASI and yield components under drought in maize. Six QTL were identified on chromosomes 1, 2, 5, 6, 8 and 10 , accounting together for approximately $50 \%$ of the phenotypic variability of ASI. The QTL segments were stable over years and stress levels. In contrast, all but two yield QTL were inconsistent in their position in the genome in different water regimes. At one important genomic position, the allele contributing to a reduction in ASI also contributed to a grain yield decrease, and for this reason CIMMYT's marker-assisted selection strategy for drought tolerance is now based on an index of best QTL for both traits [38].

Preliminary results suggest that MAS based on a strategy combining both ASI and grain yield QTL identified under drought could be a powerful tool to improve drought tolerance in tropical maize inbred lines and perhaps also in open-pollinated populations. It is 
noteworthy that, when mapped in the same F2 population as was ASI under drought, ASI under low $\mathrm{N}$ has several QTL in common with those observed under drought. So that it was expected that improvements in ASI using marker-assisted selection should also result in improvements in tolerance to low $\mathrm{N}$.

The advent of marker assisted selection opens up real prospects for new strategies in breeding that combine conventional and marker technologies that suit the genetics of the both the trait and the plant.

- Molecular markers allow the handling of very large numbers of genotypes during backcrossing while giving the breeder the tools to quickly reduce those numbers, based on their genomic composition.

- Large-scale F2 marker assisted selection schemes for developing elite, trait-enriched populations fixed for traits of interest and segregating elsewhere are an exciting prospect for programs dedicated to developing broadly-based, elite, value-added germplasm.

- Marker-assisted selection opens the possibility of testing the desirability of specific traits by developing near isogenic lines that differ only for the DNA segments associated with the trait of interest a tremendous tool for physiologists involved in testing the value and importance of secondary traits in selection.

\section{Achievements in maize breeding for low nitrogen tolerance}

Several studies [17] have highlighted good performance of tropical maize genotypes selected for drought tolerance under low $\mathrm{N}$ conditions. Lafitte and Banziger [17] reported that four maize populations (Tuxpino Sequia C8, Laposta Sequia C3, POOL 26 Sequia and POOL $18 \mathrm{C} 3$ ) improved through recurrent selection under drought combined tolerance to both drought and low N. Zambezi and Mwambula (1997) also found that improvement of drought tolerance in a maize population, Tuxpino Sequia, resulted in improved performance under low $\mathrm{N}$.

Ethiopian Institute of Agricultural Research (EIAR) has long time collaboration with the International Maize and Wheat Improvement Center-CIMMYT and it has developed a total of $40 \mathrm{im}$ proved Maize varieties-including hybrids and OPVs in the last four decades [39].

OPVS have been more common in drought prone area through the farmers in the central rift valley and several nitrogen-use efficient maize varieties, namely, Melkassa II, III, IV and V were developed in the 1990s under the first phase of the African Maize Stress (AMS) project, a joint undertaking of the International Maize and Wheat Improvement Center (CIMMYT) and national agricultural research institutes across Eastern and Southern Africa [40,41]. These varieties were specifically adapted to the semiarid agroecologies of Ethiopia's Rift Valley, an area comprising the central part of the country and characterized by lowland to intermediate agro-ecologies with access to relatively greater irrigation than other parts of the country. Their potentially significant impact on yields and output has been demonstrated through extensive field trials. For instance, field demonstration of Melkassa II variety in 2006/07 production season showed $22.7 \%$ average yield advantage as compared to the local varieties in the rift valley area [4247].

\section{Summary and Conclusion}

The maize plant has characteristics of wide adaptability in the different ranges of growing condition. Thus, it has gained adaptation and productivity in all continents through introductions and breeding. The genetic diversity of maize, being an out crossing crop, is very broad for conservation and utilization in breeding programs. Maize being an outcrossing crop and utilization of biotechnological tools including tissue culture techniques favoured several promising opportunities to manipulate the genetic constitution of the crop for the achievement of several breeding objectives (increased productivity, quality, adaptation, stability in production and biotic and abiotic stresses etc). However, the full potential of the crop has not been utilized effectively with respect to abiotic stresses particularly for low $\mathrm{N}$ stress in developing countries in order to feed ever increasing population growth and mitigate continuously occurring climatic and environmental vagaries. Since, in order to utilize the full genetic potential of the crop efficiently and effectively in sustainable manner, multi-desplinary team working with countries having strong breeding programs and acquisition of germplasms from the area of genetic diversity and evaluation under representative environment should be in the first glance.

\section{Bibliography}

1. Purseglove PW. "Tropical crops". Monocotyledons. Longman Group Ltd, London, Reference book on tropical grasses and monocotyledons, describing growth conditions, land husbandry and diseases for each crop (1976): 607.

2. McCann J. Maize and Grace: Africa's encounter with a new crop, 1500-2000. Harvard University Press, New York (2005).

3. Poehlman JM. "Breeding Field Crops”. AVI Publ. Co. Inc. Westport Connecticut (1987): 451-507.

4. Ribaut JM and D Hoisington. "Marker-assisted selection: new tools and strategies". Trends in Plant Science 3 (1998): 236239.

5. Legesse BW., et al. "Combining ability and hetrotic grouping of highland transition maize inbred lines". African Crop Science Journal Conference proceedings 9 (2011): 487-491.

6. Mossisa W., et al. "Performance of variety cross hybrids of maize (Zea mays L.) in the mid-altitude and high land transitional areas of Ethiopia”. East African Journal of Sciences 3.1 (2011): 80-84.

7. Dhillon BS and Prasanna BM. "Maize. In V. L. Chopra (ed.). Breeding Field Crops: Theory and Practice. Oxford and IBH, New Delhi (2001).

8. Hallauer AR. "Hybrid development and population improvement in maize by reciprocal full-sib selections". Egyptian Journal of Genetics and Cytology 2 (1973): 84-101. 
9. Mertz ET., et al. "Mutant gene that changes protein composition and increases lysine content of maize endosperm". Science 145.3629 (1964): 279-280.

10. Betràn FJ., et al. "Genetic Analysis of Inbred and Hybrid Grain Yield under Stress and Nonstress Environments in Tropical Maize". Crop Science 43 (2003): 807-817.

11. Zaidi PH., et al. "Relationship Between Line Per Se and Cross Performance Under Low Nitrogen Fertility". In Tropical Maize (Zea Mays L.). Maydica, 48 (2003): 221-231.

12. Below FE. "Growth and productivity of maize under nitrogen stress". In: Edmeades, G. O., Banziger, M., et al. "Developing drought- and low N-tolerant maize. CIMMYT, Mexico City, CIMMYT, El Batan, Mexico (1997): 235-240.

13. Bänziger M., et al. "Breeding for Drought and Nitrogen Stress Tolerance in Maize: From Theory to Practice". Mexico, D.F. CIMMYT (2000).

14. Emede TO and Alika JE. "Variation in agronomic characters among high and low nitrogen S2 maize (Zea mays L) lines grown in high and low nitrogen environments". Maydica 57 (2012): 139-146.

15. Hirel B., et al. Improving Nitrogen Use Efficiency in Crops for Sustainable Agriculture Sustainability 3 (2011): 1452-1485.

16. Bello OB and G Olaoye. Combining ability for maize grain yield and other agronomic characters in tropical southern Guinea Savanna ecoclogy of Nigeria (2009).

17. Lafitte HR and Edmeades GO. "Improvement for tolerance to low soil nitrogen in tropical maize I. Selection criteria”. Field Crops Research 39.1 (1994): 1-14.

18. Sprague GF and Tatum LA. "General vs specific combining ability in single crosses of corn". Journal American Society Agronomy 34 (1942): 923-932.

19. Falconer DS and Mackay TFC. Introduction to Quantitative Genetics, Longman Group Ltd (1996).

20. Tamilarasi PM., et al. "Identification of Nitrogen (N) Stress Tolerant Maize (Zea Mays L.) Inbred Lines for Low Nitrogen Input Condition". Indian Journal of Agricultural Research 44.11 (2010): 53-57.

21. Gardner CO and Eberhart SA. "Analysis and interpretation of the variety cross diallel and related populations". Biometrics 22 (1996): 439-452.

22. Griffing B. "Concept of general and specific combining ability in relation to diallel crossing systems". Australian Journal of Biological Science 9 (1956): 463-493.

23. Akintoye HA., et al. "N use efficiency of single, double and synthetic maize lines grown at four $\mathrm{N}$ levels in three ecological zones of West Africa". Field Crops Research 60.3 (1999): 189199.
24. Mi G., et al. "Physiological and genetic mechanisms for nitrogen-use efficiency in maize". Journal of Crop Science Biotechnology 10.2 (2005): 57-63.

25. Vasal SK., et al. "Choices among breeding procedures and strategies for developing stress-tolerant maize germplasm". In: G.O. Edmeades et al. (eds.), Developing Drought- and Low N-Tolerant Maize. Proceedings of a Symposium, March 25-29, 1996, CIMMYT, El Batán, Mexico. Mexico, D.F. CIMMYT (1997): 336-347.

26. Miti F., et al. "S1 selection of local maize landraces for low soil nitrogen tolerance in Zambia". African Journal of Plant Science 4.3 (2010): 67-81.

27. Dudley JW. "A method of identifying lines for use in improving parents of a EARO (2000). Research strategy for maize. Ethiopia Agricultural Research Organization (EARO), Addis Ababa, Ethiopia (1984).

28. Bolaños J and Edmeades GO. "The importance of the anthesis silking interval in breeding for drought tolerance in tropical maize". Field Crops Research 48 (1996): 65-80.

29. Moll R., et al. "Analysis and interpretation of factors which contribute to efficiency of nitrogen utilization". Agronomy Journal 74 (1982): 562-564.

30. Bruce WB., et al. "Molecular and physiological approaches to maize improvement for drought tolerance". Journal of Experimental Botany 53 (2002): 13-25.

31. Bertin P and Gallais A. "Physiological and genetic basis of nitrogen use efficiency in maize: I. Agrophysiological results". Maydica 45 (2000): 53-66.

32. Gallais A and Coque M. "Genetic variation and selection for nitrogen use efficiency in maize: a synthesis". Maydica 50.3 (2005): 531-547.

33. Hallauer AR., et al. "Quantitative Genetics in Maize Breeding". New york, Springer (2010): 663.

34. Shull GH. "Beginnings of the heterosis concept". In: Gowen, J. (Ed.) Heterosis Iowa State University Press Ames (1952): 1448.

35. Makumbi D. "Phenotypic and genotypic characterization of white maize inbreds, hybrids and synthetics under stress and non-stress environments". PhD Thesis, Texas A and M University (2005): 221.

36. Abrha SW., et al. "Line $\mathrm{x}$ tester analysis of maize inbred lines for grain yield and yield related traits". Asian Journal of Plant Science and Research 3.5 (2013): 12-19.

37. Beck D., et al. "From landrace to hybrid: strategies for the use of source populations and lines in the development of drought tolerant cultivars". In G.O. Edmeades, M. Bänziger, H.R. Mickelson, and C.B. Peña-Valdivia (eds.), Developing Drought and Low N-Tolerant Maize. Proceedings of a Symposium, March 25-29, 1996, CIMMYT, El Batán, Mexico, 369-382. Mexico, D.F.: CIMMYT (1997) 369-382. 
38. Ribaut JM., et al. "Identification of quantitative trait loci under drought conditions in tropical maize. 2. Yield components and marker-assisted selection strategies". Theoretical and Applied Genetics 94 (1997): 887-896.

39. Eyob B. National government vs Cimmyt investment trends in maize research: The case of EIAR Research Journal of Agriculture and Environmental Management 4.4 (2015): 192-196.

40. Banziger M and Diallo AO. "Progress in developing drought and $\mathrm{N}$ stress tolerant maize cultivars for Eastern and Southern Africa". Paper presented at the Seventh Eastern and Southern Africa Regional Maize Conference, 5-11 Nairobi, Kenya (2002).

41. Worku M., et al. "Developing low $\mathrm{N}$ tolerant maize varieties for mid-altitude sub-humid agro-ecology of Ethiopia”. Paper presented at the Seventh Eastern and Southern Africa Regional Maize Conference, 5-11 February, Nairobi, Kenya (2002).

42. Bedru Beshir. "Maize demonstration and evaluation in the Rift Valley". Progress report. Melkassa Research Center. Ethiopian Institute of Agricultural Research (2007).

43. Acquaah G. "Principles of Plant Genetics and Breeding". U K, Blackwell Publishing”. Agronomy Journal 41 (2006): 360-367.

44. CSA (Central Statistical Authority), Federal Democratic Republic of Ethiopia Statistical Abstracts. Addis Ababa: CSA (2006).

45. CSA (Central Statistical Authority), Federal Democratic Republic of Ethiopia Statistical Abstracts. Addis Ababa: CSA (2001).

46. Dowswell Christopher R., et al. "Maize in the Third World". New York: Westview (1996).

47. Edmeades GO., et al. "Value of secondary traits in selecting for drought tolerance in tropical maize. In: G.O. Edmeades et al. (Eds.), Developing Drought- and Low N-Tolerant Maize. Proceedings of a Symposium, March 25-29, 1996, CIMMYT, El Batán, Mexico. Mexico, D.F. CIMMYT (1996): 222-234.

48. Logrono M and Lothrop JE. "Impact of drought and low nitrogen on maize production in Asia". In: Edmeades, G. O. E. A. (Ed.) Developing Drought- and Low N-Tolerant Maize. Mexico, D.F., CIMMYT/UNDP (1997).

49. Machado AT and Fernandes MS. "Participatory maize breeding for low nitrogen tolerance”. Euphytica 122 (2001): 567-573. 